\title{
POR UMA METODOLOGIA DE ENSINO JURÍDICO QUE VALORIZE A DIVERSIDADE RACIAL, DENTRO E FORA DA SALA DE AULA
}

Poliana da Silva Ferreira ${ }^{1}$

\section{RESUMO}

Este texto tem por objetivo apresentar uma reflexão acerca da metodologia de ensino jurídico implementada no Brasil. Parte-se da necessidade de repensar a forma segundo a qual o Direito é ensinado nas instituições de ensino superior, as quais têm priorizado uma relação professoraluno verticalizada, construída de maneira unilateral e descontextualizada. Soma-se a esses elementos o fato dessa metodologia ignorar os novos sujeitos de direito - negros e negras, pessoas oriundas de classes populares e aqueles e aquelas pertencentes a comunidades indígenas - que reivindicam o acesso e a permanência no ensino superior, o que inclui os cursos de Direito. A estratégia metodológica adotada privilegia a revisão de literatura. Ao fim, argumenta-se pela indispensabilidade de uma metodologia de ensino jurídico que valorize a diversidade racial do país e que, para isso, congregue uma abordagem antirracista, o que engloba um completo deslocamento epistemológico e cognitivo em algumas áreas.

Palavras-chave: Metodologia de ensino. Ensino jurídico. Diversidade racial. Ações afirmativas.

${ }^{1}$ Escola de Direito de São Paulo, Fundação Getúlio Vargas, São Paulo, SP, Brasil. 


\title{
FOR A LEGAL EDUCATION METHODOLOGY THAT VALUES RACIAL DIVERSITY, IN AND OUT OF THE CLASSROOM
}

Poliana da Silva Ferreira

\begin{abstract}
This text aims to present a reflection about the methodology of Legal Education implemented in Brazil. It starts from the necessity to rethink the way in which Law is taught in higher education institutions, which have prioritized a vertical teacher-student relationship, built unilaterally and decontextualized. In addition to these elements, this methodology ignores the new subjects of law - black men and women, people from the popular classes and those who belong to indigenous communities - who claim access to and stay in higher education, which includes the Law courses. The methodological strategy adopted favors the literature review. In the end, one argues for the indispensability of a legal teaching methodology that values the racial diversity of the country and, for that, needs to congregate an anti-racist approach, which encompasses a complete epistemological and cognitive shift in some areas.
\end{abstract}

Keywords: Teaching methodology. Legal education. Racial diversity. Affirmative actions. 


\section{INTRODUÇÃO}

O ensino jurídico no Brasil tem sido objeto de estudos que se baseiam em diferentes recortes e abordagens. Sua tematização encontra amparo em pesquisas que se dedicam desde questões mais abrangentes, como é o caso da chamada "crise do ensino jurídico" (LAMY FILHO, 1972; MARCHESE, 2006; RODRIGUES, 1992), àquelas que lidam com problemas mais específicos, como a formação e a carreira do professor no âmbito do Direito (MUSSE; FREITAS FILHO, 2015). No entanto, ainda são escassas as pesquisas ${ }^{2}$ que exploram as relações entre ensino jurídico, diversidade e desigualdade racial.

Este texto detém-se sobre um ponto específico da desigualdade racial no campo do Direito: a metodologia de ensino jurídico. Assim, o objetivo do presente artigo é propor uma reflexão acerca da necessidade de uma metodologia de ensino jurídico que valorize a diversidade racial do país, com especial ênfase nos aspectos ligados à negritude.

No Brasil, a desigualdade racial traduz-se no fato de que, apesar de haver uma diversidade étnico racial - oriunda do processo de colonização das terras brasileiras por povos europeus e dos processos de escravização das comunidades indígenas aqui residentes e dos povos de países africanos trazidos à força -, alguns segmentos sociais sobrevivem em condições sociais, políticas e econômicas superiores à esmagadora maioria da população. ${ }^{3} \mathrm{Na}$ contramão dos privilégios está a população negra.

Negros e negras são vítimas preferenciais da violência policial, permanecem menos tempo na escola, ganham menos da metade do salário de homens brancos, são vítimas constantes de injúria racial, permanecem invisíveis nos meios de comunicação de massa e estão

\footnotetext{
${ }^{2}$ A primeira etapa da pesquisa da qual este artigo resulta consistiu na busca on-line por pesquisas dedicadas à metodologia de ensino no Direito, à diversidade e à desigualdade raciais, realizada entre os meses de setembro e outubro de 2017, no Google Acadêmico e no Catálogo de Teses e Dissertações da Coordenação de Aperfeiçoamento de Pessoal de Nível Superior (CAPES). Disponível em: http://catalogodeteses. capes.gov.br/catalogo-teses/\#!/. Acesso em: 30 set. 2018.

${ }^{3}$ Não obstante a desigualdade racial gerar consequências perversas que inviabilizam o desenvolvimento socioeconômico de outros grupos étnico-raciais, como os oriundos de comunidades indígenas, neste texto priorizam-se as disparidades e as discrepâncias entre brancos e negros. Tematiza-se, portanto, o racismo antinegro(a), ou antinegritude (VARGAS, 2010, 2017), uma vez que, apesar de constituírem-se maioria da população brasileira segundo o Censo 2010 do Instituto Brasileiro de Geografia e Estatística (IBGE), os negros são a parcela da população que paradoxalmente enfrenta barreiras mais agudas para acessar bens, como saúde, educação, emprego, renda.
} 
estruturalmente excluídos de cargos de poder nas instituições públicas e nas instituições privadas (MOREIRA, 2016, p. 131).

Por ser estrutural, uma vez que "há mecanismos de discriminação inscritos na operação do sistema social e que funcionam, até certo ponto, à revelia dos indivíduos" (GUIMARÃES, 1999, p. 156), a desigualdade racial também é um elemento constituinte do Direito brasileiro e manifesta-se não só do ponto de vista normativo (o que inclui sua produção), mas, também, do ponto de vista das práticas profissionais e institucionais.

Para tratar o tema, adota-se como estratégia metodológica uma revisão da literatura dos estudos sobre relações raciais, racismo, ensino jurídico e metodologia de ensino. O texto está dividido em três partes. Na primeira, explicita-se de que forma o Direito tem sido tradicionalmente ensinado nas faculdades brasileiras, discutindo seus pressupostos e os lugares conferidos à metodologia do ensino no arcabouço normativo que instituiu não só o curso no Brasil, mas, também, as diretrizes mais atuais.

Na segunda parte, mostra-se como as políticas de ações afirmativas implementadas no ensino superior, de forma geral, e, especificamente, no campo do Direito, permitiram o ingresso de estudantes negros como sujeitos de direito na disputa por acesso à educação superior pública. Esse fato proporcionou mudanças de perspectivas no ensino jurídico, impulsionando a necessidade de uma nova metodologia de ensino que incorpore a diversidade racial do Brasil, o que será identificado e valorizado na terceira parte deste artigo.

\section{OS PRESSUPOSTOS DO ENSINO JURÍDICO TRADICIONAL E O LUGAR DA METODOLOGIA DE ENSINO NOS CURSOS DE DIREITO NO BRASIL}

Tradicionalmente, o ensino do Direito no Brasil se preocupou em formar pessoas oriundas da elite econômica em quadros da elite política, jurídica e administrativa do país, fato que se refletiu nos métodos adotados para alcançar o referido objetivo. Nesse sentido, a metodologia de ensino envolveu tradicionalmente um ambiente de poucas trocas acadêmicas, hierarquizado, muitas vezes alheio ao contexto político e social externo à sala de aula, por meio do "método prelecional clássico, da chamada 'aula douta coimbrã', com o desfile de citações mais ou menos eruditas e a exegese de textos de lei" (LAMY FILHO, 1972, p. 6). 
A lei, a doutrina e a dogmática firmaram-se como as principais fontes para a produção de um saber jurídico plausível de ser ensinado em sala de aula. Assim, o ensino jurídico tradicional se caracteriza por ter como eixo "o estudo das leis, por intermédio da doutrina" (VIEIRA, 2012, p. 380), pela presença de um jurista cuja preocupação central é a "justificação do exercício da sua autoridade" (VARGAS, 2014, p. 83) e por uma escola que está ancorada essencialmente "em um modelo de ensino peculiar, baseado em aulas expositivas e análises de decisões (quase sempre) 'corretas' tomadas por magistrados" (VARGAS, 2014, p. 83).

Essa forma de produzir e compartilhar saber jurídico se sustenta em um ensino baseado, sobretudo, em opiniões, crenças e concepções que não necessariamente estariam ancoradas em dados, em conhecimento empírico ou teriam qualquer correspondência com a realidade, conforme apontam Baptista e Lima (2014). A consequência direta desse diagnóstico está no fato de que as fontes da produção desse saber - leis, livros e manuais de Direito - tornamse insuficientes para compreender de maneira apropriada o campo jurídico e as lógicas que amparam o sistema judiciário.

Algumas causas podem ser levantadas para explicar por que essa metodologia de ensino perdurou por tantos anos. Aqui, elegemos duas, uma mais remota, e outra mais recente. $A$ primeira está na influência exercida pelos primeiros cursos de Direito do país, mediante a promulgação da Lei de 11 de agosto de 1827, sancionada pelo imperador D. Pedro I, cujo objetivo era atender às necessidades burocráticas impostas pelo período imperial. A lei foi acompanhada de "Projeto de regulamento ou estatuto para o Curso Jurídico", documento promulgado por meio de decreto, cuja função era organizar os primeiros cursos jurídicos do Brasil, em São Paulo e em Olinda. Entre outras determinações, a referida normativa dispunha sobre a forma de ingresso, o plano de curso, as matérias que deveriam ser ensinadas e de que forma, em cada ano. Tudo concatenado com a cultura jurídica liberal que dominava à época (FALCÃO, 1981).

A norma, que foi elaborada e implementada de maneira unilateral, da elite para a elite, além de conter rigidez e pragmatismo excessivos, apresentava um forte caráter autoritário, que determinava desde como o professor distribuiria o tempo da aula - "O Professor gastará a primeira meia hora em ouvir as lições, e o mais tempo em explicar o compêndio" (BRASIL, 1827), como descrito no capítulo X da referida norma - até as férias, no capítulo XVI, do mesmo diploma legal. Cabe salientar, ainda quanto a esse elemento causal, o contexto social 
da época, o qual contava com uma maioria de pessoas vivendo em regime de extrema pobreza e miséria.

$\mathrm{Na}$ independência, em 1822, o Brasil tinha provavelmente uma população entre 4,5 e 4,8 milhões e cerca de um terço era escrava [...]. Em 1850, a população brasileira era de cerca de 7,5 milhões, com os escravos respondendo ainda por cerca de $30 \%$ do total [...]. O censo de 1872 revelaria 10,1 milhões de habitantes, com a população escrava excedendo 1,5 milhão. 0 recenseamento de 1890 situou a população brasileira em 14,3 milhões. Três anos antes, em 1886/87, às vésperas da abolição da escravidão, ainda existiam pouco mais de $700 \mathrm{mil}$ escravos (ABREU; LAGO, 2001, p. 2).

Ao lado da escravidão da população negra, que já colocava esse grupo étnico-racial em posição de desumana subalternização, persistiam ao longo do século XIX condições de desigualdades sociais e econômicas, que distanciavam estratos de diferentes segmentos sociais. Nesse contexto, há um Brasil majoritariamente rural, analfabeto, sem saneamento básico e que se sustentava do trabalho braçal (ADORNO, 1988; OLIVEN, 1999; TEIXEIRA, 1994).

Do ponto de vista do campo do Direito, o surgimento dos primeiros cursos, deslocados da realidade social e pautados no legalismo positivista vigente à época, marcou um período caracterizado por um ensino jurídico em que, segundo Marcos Nobre, "até a primeira metade do século XX, o direito era em larga medida identificado aos obstáculos a serem vencidos: a falta de rigor científico, o ecletismo teórico e uma inadmissível falta de independência em relação à política e à moral" (NOBRE, 2013, p. 146). Portanto, a maneira de se ensinar o Direito hoje tem não só raízes históricas, cujas heranças podem ser encontradas em qualquer sala de aula em que se lecione processo civil, por exemplo, mas, também, expressa a maneira segundo a qual o próprio Direito se enxerga e se lê (BAPTISTA; LIMA, 2014).

A segunda causa, de natureza mais recente, consiste na ausência de uma reforma do ensino que trate especificamente da metodologia adotada pelos professores e professoras do Direito, não obstante a profunda reforma pela qual passou o ensino jurídico no Brasil, há pouco mais de uma década, a partir da Resolução $n^{\circ} 9,{ }^{4}$ de 29 de setembro de 2004, do Conselho

\footnotetext{
${ }^{4}$ Além dessa resolução, outros instrumentos normativos já haviam sido utilizados para alterar as diretrizes curriculares do curso de Direito, como a Portaria $n^{\circ}$ 1.886, de 30 de dezembro de 1994, do Ministério da Educação (MEC), a qual fixava as diretrizes curriculares e o conteúdo mínimo do curso jurídico.
} 
Nacional de Educação/Câmara de Educação Superior (CNE/CES), a qual instituiu as diretrizes curriculares nacionais do curso de graduação em Direito.

A referida normativa resultou tanto de movimentos da sociedade civil quanto de instituições públicas ligadas ao ensino e respondeu, em alguma medida, ao fenômeno identificado por vários autores como uma crise do ensino jurídico (VIANNA, 1974 apud VIEIRA, 2012, p. 381).

Ao estudar a crise do ensino jurídico de graduação no Brasil contemporâneo, Horácio Wander de Rodrigues (1992) aponta que trata-se de uma crise do direito e da cultura jurídica. Fazendo referência a San Tiago Dantas, o referido autor pontua que o problema da educação jurídica poderia ser visto sob duas óticas. Na primeira, a partir de uma noção de projeção ampla, observam-se as dificuldades gerais que alcançam o ensino superior e todo o sistema educacional. Na segunda, de forma mais restrita, são apontados os problemas na própria cultura jurídica. Para Rodrigues,

[o] ensino jurídico, fazendo parte do mundo do Direito, reflete tanto a crise deste como a do sistema sócio-político-econômico em sua totalidade. A sua estrutura e as várias funções por ele desempenhadas começam também a ser questionadas. A análise dessa situação, bem como a busca de soluções efetivas, em nível do ensino, é fundamental. O Direito desempenha nas sociedades modernas um papel essencial nos níveis simbólico e material. Encontrar respostas que viabilizem a superação da sua crise e do seu ensino é resgatar a sua função social (RODRIGUES, 1992, p. 29).

Entre as causas desta crise apontadas pelos estudiosos, poderíamos pontuar aquela identificada por Marcos Nobre:

o problema que vem sendo sistematicamente identificado nas análises sobre a questão é o fato de o ensino jurídico estar fundamentalmente baseado na transmissão dos resultados da prática jurídica de advogados, juízes, promotores e procuradores, e não em uma produção acadêmica desenvolvida segundo critérios de pesquisa científica (NOBRE, 2013, p. 147).

Ainda quanto ao contexto em que se erigiu a Resolução CNE/CES n 9/2004, deve-se destacar o número excessivo de criação de faculdades de Direito, cursos autorizados sem condições estruturais mínimas, baixa quantidade de professores pós-graduados (LEITE; DIAS, 2014). Apesar de tentar enfrentar alguns desses problemas e tocar em pontos centrais ao ensino do 
Direito, como é o caso do projeto pedagógico - o que inclui o perfil do formando, os conteúdos curriculares, o estágio curricular supervisionado, as atividades complementares, o sistema de avaliação e a duração do curso, entre outros -, a Resolução CNE/CES n 9/2004 peca em não oferecer diretrizes acerca de uma metodologia de ensino inclusiva, que permita o diálogo com os novos sujeitos sociais, que, à época, já ingressavam nos cursos de Direito do país (esse ponto será aprofundado na próxima seção).

A referida normativa faz menção aos termos "método" e "metodologia" de ensino apenas uma vez. De um lado, a existência desses termos nos informa a respeito das tentativas institucionais por parte do CNE de oferecer um ensino que desconstrua e desnaturalize as representações sociais sobre o real que os cursos de Direito tradicionalmente foram capazes de produzir (BAPTISTA; LIMA, 2014), mas que, por outro lado, ainda não são suficientemente delineadas. As menções estão: no artigo $4^{\circ}$, inciso VIII, o qual se refere a "domínio de tecnologias e métodos para permanente compreensão e aplicação do Direito" (BRASIL, 2004) quando trata das habilidades e das competências que deverão ser promovidas pelo curso de graduação em Direito na formação profissional; e, em relação ao termo "metodologia", no artigo 9, parágrafo único, no qual se pode ler que "[o]s planos de ensino, a serem fornecidos aos alunos antes do início de cada período letivo, deverão conter, além dos conteúdos e das atividades, a metodologia do processo de ensino-aprendizagem" (BRASIL, 2004), ao abordar as formas específicas de avaliação a serem adotadas pelas instituições de educação superior.

Portanto, reafirmam-se a negligência e a desídia históricas a respeito da importância da metodologia de ensino jurídico, não qualquer uma, mas aquelas que prezem não só pela relação com o contexto político, social e regional, mas pela inclusão da parcela da população brasileira, até então excluída, que passa a ter acesso recente, em larga escala, ao ensino superior nos cursos de Direito, que foram muitas vezes desenhados de forma excludente (TEIXEIRA MENDES, 2005).

\section{AS MUDANÇAS QUE VÊM DE FORA: AS AÇÕES AFIRMATIVAS}

Nos últimos anos, a sociedade brasileira tem assistido a algumas mudanças significativas, de forma geral, no cenário do ensino superior e, especificamente, nos cursos de Direito. A origem destas transformações pode ser atribuída, entre outros fatores, à implementação de ações afirmativas, a partir de 2002, e às respostas inerentes à mercantilização do ensino jurídico no ambiente privado. 
Em sentido amplo, as ações afirmativas podem ser entendidas como "medidas redistributivas que visam a alocar bens para grupos específicos" (DAFLON; FERES JÚNIOR; CAMPOS, 2013, p. 306), isto é, políticas públicas que têm por objetivo reduzir desigualdades sociais e raciais de segmentos sociais historicamente discriminados. Nesse contexto, encontra-se uma série de disposições legais, oriundas de articulações políticas entre poder público e movimentos sociais, como programas de regularização fundiária, distribuição de moradia, acesso diferenciado a medicamentos específicos a grupos vulneráveis. Portanto, podemos considerar que as ações afirmativas se consubstanciam em estratégias ou mecanismos de enfrentamento ao racismo estrutural e institucional.

Em sentido estrito, conceitua Adilson José Moreira,

As ações afirmativas são políticas sociais destinadas à criação de uma representação significativa de membros de grupos minoritários nas posições de poder existentes dentro da sociedade. Como uma prática institucional, elas adotam procedimentos que utilizam os mesmos critérios responsáveis pela exclusão social para garantir a inclusão de minorias. Agentes públicos e privados conferem um tratamento preferencial a membros de grupos que estão em uma situação de desvantagem durante um determinado período de tempo (MOREIRA, 2016, p. 132).

Segundo Kabengele Munanga (2003), as políticas de ação afirmativa são consideradas recentes na história do enfrentamento ao racismo. O referido autor argumenta que nos países onde essas políticas já foram implementadas, a exemplo de Estados Unidos (desde a década de 1960), Canadá, Índia e Alemanha, elas visavam conceder aos grupos historicamente discriminados um tratamento diferenciado para corrigir as desvantagens devidas a sua situação de vítimas do racismo ao longo da história e de outras formas de discriminação, "[...] daí as terminologias de 'equal opportunity policies', ação afirmativa, ação positiva, discriminação positiva ou políticas compensatórias" (MUNANGA, 2003, p. 117).

Segundo o sociólogo Antônio Sergio Guimarães (2005), a bandeira de luta por acesso ao ensino superior foi levantada por jovens autodeclarados negros, que reivindicavam o ingresso nas universidades públicas como forma de alterar o profundo quadro de desigualdade no qual o Brasil estava imerso, herança do período escravocrata e das perversas consequências oriundas da ausência de políticas públicas de cunho reparatório e/ou compensatório desde então. Além dos jovens negros, os indígenas e os egressos do ensino médio público também compunham os segmentos sociais que pleitearam as ações afirmativas para ingresso no ensino superior. 
No campo específico do Direito, o ingresso e a permanência de alunas e alunos negros, oriundos de comunidades indígenas e de escolas públicas representam um avanço, não só no plano simbólico, mas também no plano social e econômico, dado que o curso de Direito abre o caminho para carreiras que promovem a ascensão social rapidamente, conforme demonstrado em pesquisas desenvolvidas por Jocélio Teles dos Santos e Delcele Mascarenhas Queiroz (2006), no estado da Bahia, a respeito do ingresso dos referidos alunos em cursos almejados, como Direito, Medicina e Engenharia.

No mesmo sentido, a pesquisa realizada por Paulo Gabriel Hilu da Rocha Pinto (2005) sobre a entrada, a permanência e o desempenho de alunos cotistas em cursos de "prestígio social elevado", como Medicina, Odontologia e Direito, na Universidade Estadual do Rio de Janeiro apontou que a inserção de alunos cotistas no universo acadêmico não pode ser abordada apenas pelos interesses calculados nas disposições que organizam as práticas acadêmicas, ou com reformas das técnicas pedagógicas e dos conteúdos curriculares, sobretudo quando consideradas a informalidade e a pessoalidade das relações pedagógicas no cotidiano das universidades brasileiras (PINTO, 2005). A chave da valorização da diversidade dentro e fora da sala de aula congrega as possibilidades criadas pelas instituições que aderiram às cotas para que esses sujeitos possam se manter nas universidades e criar trajetórias acadêmicas de sucesso sem abrir mão de marcadores de pertencimento e identidade.

A entrada desses novos sujeitos de direito nos cursos de Direito promoveu, inevitavelmente, uma mudança de paradigma nas salas de aula, nos cursos que aderiram a programas ligados às ações afirmativas, no que diz respeito à forma de ensinar e de aprender. Pode-se dizer que, em última instância, houve uma ruptura da própria lógica que deu origem a esses cursos no Brasil: esses alunos, oriundos de realidades sociais complexas, exigem um novo Direito, um Direito que dialogue com as necessidades de suas comunidades, favelas, aldeias, cidades.

O ingresso dos novos estudantes coloca no centro do debate as fissuras estabelecidas entre os discursos legitimadores da desigualdade racial no Brasil, como é o caso do mito da democracia racial, e as falas daqueles que vivenciam o cotidiano de uma sociedade desigual. Esse abismo se consubstancia, aliás, nos currículos que silenciam as contribuições acadêmicas de autoras e autores negros (CARNEIRO, 2005), nas linhas de pesquisas que ignoram o papel do Direito, e de suas respectivas instituições, como reprodutor de violências raciais. Da mesma forma, existem planos de aula que se sustentam epistemologicamente em quadros teóricos cujos alicerces empíricos são constituídos pelas experiências pessoais dos docentes, as quais, não 
raramente, baseiam-se em privilégios da branquitude, ${ }^{5}$ ou, ainda, em programas que se autodefinem críticos, mas priorizam em seus projetos pedagógicos a leitura da desigualdade social baseada no recorte de classe como única explicação possível ao atual quadro político, jurídico e econômico do país.

\section{METODOLOGIAS DE ENSINO PARA CONTEXTOS PLURAIS}

É dentro deste contexto acadêmico, portanto, que se impõe a necessidade de uma metodologia de ensino que valorize a diversidade racial, o que exige uma reformulação das matrizes curriculares tradicionais no curso de Direito. Nesta seção, são apresentados alguns exemplos de abordagens que, pela forma ou pelo conteúdo, expressam as disputas entre o ensino jurídico tradicional e a necessidade de novas narrativas no ensino do Direito.

Um primeiro exemplo é o do ensino dos direitos humanos. Já não se sustenta a única narrativa de surgimento dos direitos humanos, como direitos fundamentais, lida a partir da universalização da experiência branca ocidental no contexto da Segunda Guerra Mundial, a partir do Holocausto judeu, assim como da emergência do crime de genocídio e da sua responsabilização no Tribunal Penal Internacional. Essa leitura ignora barbáries similares que ocorreram nos países africanos, com a contribuição, e até com o apoio, em alguns casos, dos países europeus e não problematiza a disputa político-jurídica sobre o conceito de genocídio provocada pelos movimentos sociais e pelos acadêmicos brasileiros a partir do chamado "genocídio da juventude negra" no Brasil.

Outro exemplo está no campo do Direito Penal, do Direito Processual Penal e da Criminologia, guardadas as devidas particularidades que circunscrevem cada uma dessas disciplinas. Teorias que descrevem, explicam ou prescrevem comportamentos, práticas, padrões e maneiras de pensar sobre o crime, o criminoso, o controle social e os processos de vitimização, desprezando as funções que o marcador social "raça" tem nas origens, não só nas disciplinas como tais, mas também como campo de estudo, pesquisa e de atuação profissional.

\footnotetext{
${ }^{5} \mathrm{~A}$ branquitude pode ser entendida como a construção sócio-histórica que está baseada na ideia de superioridade racial branca, "em que os sujeitos identificados como brancos adquirem privilégios simbólicos e materiais em relação aos não brancos" (SCHUCMAN, 2012, p. 12). A branquitude "se refere a um lugar de poder, de vantagem sistêmica nas sociedades estruturadas pela dominação racial" (SCHUCMAN, 2012, p. 102).
} 
Nesse contexto, tem-se: uma Criminologia cujos fundamentos ancoram-se em explicações etiológicas para compreender o fenômeno criminal, que, conforme aponta Marcos Alvarez, à época da implementação desse campo de estudo no país, nas últimas décadas do século XIX, representava simultaneamente a possibilidade "de compreender as transformações pelas quais passava a sociedade, de implementar estratégias específicas de controle social e de estabelecer formas diferenciadas de tratamento jurídico-penal para determinados segmentos da população" (ALVAREZ, 2002, p. 696); uma Criminologia Crítica que explica o comportamento criminoso a partir de uma ótica de desigualdade social, baseada exclusivamente no método dialético de estudo, sugerindo as desigualdades econômicas como determinantes do comportamento criminoso e "da posição de classe como variável decisiva do processo de criminalização" (SANTOS, 1981, p. 29); um Direito Penal cujas interpretações das normas penais embasam-se em doutrinas nas quais o sujeito negro, o racismo e os debates a respeito de relações raciais só aparecem (quando aparecem) nos estudos do tipo penal, como injúria racial e racismo; e, ainda, um Processo Penal que menospreza as relações de poder, que beneficiam os privilegiados e não permitem a apuração dos cerca de 60 mil homicídios ${ }^{6}$ que ocorrem por ano no Brasil (WAISELFISZ, 2016), suscitam a ausência dos processos de responsabilização da polícia que mata, dentro e fora de serviço, (FLAUZINA; FREITAS, 2017; SINHORETTO; SILVESTRE; SCHLITTLER, 2014) e subestimam a capacidade de produzir corpos encarcerados por meio da Lei de Drogas (Lei $n^{\circ} 11.343 / 2006$ ).

No plano do Direito do Trabalho e Processual Trabalhista, mencionam-se a ausência de debate acerca das legislações que buscaram acomodar o trabalho escravo antes de 1888 e os mecanismos legais e institucionais que, após esse marco, permitiram a contínua desvalorização de postos de trabalho majoritariamente ocupados por pessoas negras, a legitimação de trabalhos em condições similares às de trabalho escravo, o atraso da legislação que regulamentou o trabalho doméstico, a potencial precarização das condições de trabalho e emprego com a reforma trabalhista de 2017.

Quanto à esfera do Direito Civil, por exemplo, direitos reais baseados em explicações normativas que desvalorizam a importância da forma segundo a qual brancos adquiriram terras - posse e propriedade -, benefícios fiscais e outras vantagens determinadas historicamente,

\footnotetext{
${ }^{6}$ Segundo o mapa da violência de 2016, "A vitimização negra no país que, em 2003, era de 71,7\% (morrem, proporcionalmente, 71,7\% mais negros que brancos), pula para 158,9\%, em 2014" (WAISELFISZ, 2016).
} 
que permitiram que brancos tivessem hoje o privilégio de desfrutar das áreas mais seguras, urbanizadas e com maior qualidade de vida.

Além da abordagem com a qual os professores e professoras tratarão determinado tema, em cada matéria (apenas ilustramos alguns exemplos acima, reconhecidamente incipientes), um outro desafio é imposto a esses profissionais com a entrada desses novos sujeitos de direito: o uso de tecnologias de ensino apropriadas, isto é, métodos de ensino que permitam debates horizontais, ambientes propícios à escuta, à exploração da realidade com a qual os alunos convivem, à produção coletiva do conhecimento em sala de aula - tudo isso tendo por meio e finalidade o uso e a produção de pesquisas empíricas.

É importante destacar que algumas Faculdades de Direito no Brasil já fazem uso do chamado "ensino jurídico participativo"7 como método alternativo ao ensino jurídico tradicional. Mas, cabe igualmente frisar, que essas instituições ofertam suas vagas à elite econômica do país, sendo assim, um ensino jurídico participativo não democratizado e, portanto, constituindo-se exceção no contexto acadêmico brasileiro.

Assim, a construção de uma metodologia de ensino jurídico que valorize a diversidade racial do país, precisa, necessariamente, congregar uma abordagem antirracista, o que inclui um completo deslocamento epistemológico e cognitivo em algumas áreas e um conjunto de técnicas que desnaturalize a relação de hierarquia entre o(a) professor(a) e o(a) aluno(a), considere uma pluralidade de métodos e olhares na elaboração das aulas e problematize a função do Direito tendo em vista os conflitos raciais - latentes e manifestos - em todas as disciplinas da área.

\section{CONSIDERAÇÕES FINAIS}

Este texto teve por finalidade discutir a metodologia de ensino do Direito no Brasil, com destaque à diversidade racial que este apresenta, mas, sobretudo, sinalizando a desigualdade racial que impera no país e que, portanto, inevitavelmente, atinge o Direito.

\footnotetext{
${ }^{7}$ Mais informações podem ser encontradas no site da Escola de Direito de São Paulo da Fundação Getulio Vargas. Disponível em: <http://ejurparticipativo.direitosp.fgv.br>. Acesso em: 30 set. 2018.
} 
No primeiro momento, salientaram-se as características do ensino tradicional e o lugar que foi conferido à metodologia de ensino, do ponto de vista jurídico-normativo. Assim, foi apresentada uma breve análise sobre a legislação que instituiu os cursos de Direito no Brasil, o contexto social de sua criação e sua influência na maneira segundo a qual o Direito é ensinado nos dias de hoje.

No segundo momento, valorizou-se o ingresso de alunos oriundos de políticas de ações afirmativas de cunho racial no ensino superior, em geral, mas, sobretudo, nos cursos de graduação em Direito, como impulsionador de uma nova forma de ensinar o Direito - que, não necessariamente, já ocorreu ou está ocorrendo, mas que nos ajuda a pensar como queremos que ela seja. A entrada e a permanência de novos sujeitos de direito nos cursos de Direito obriga-nos a repensar não só a abordagem com que disciplinas clássicas são ensinadas no curso, mas, também, o uso de novas ferramentas que auxiliem o processo de ensinoaprendizagem numa perspectiva antirracista.

Por fim, na terceira parte, destacou-se quanto o ensino jurídico participativo constitui-se uma exceção entre as formas adotadas para ensinar o Direito e deve ser democratizado, para que as instituições de ensino superior, especialmente as públicas, garantam aos diversos alunos o direito a um ensino não só participativo, mas também plural. A criação de uma norma jurídica que trate especificamente de metodologia de ensino jurídico participativo e antirracista é necessária, mas ainda não existe. Sua ausência demonstra que esse tema ainda não é uma prioridade na agenda política do país, mas, também, revela que o estandarte da diversidade racial acaba sendo um obstáculo ao enfrentamento da desigualdade racial e de suas respectivas manifestações na educação e no Direito, dentro e fora da sala de aula.

\section{REFERÊNCIAS}

ABREU, Marcelo P.; LAGO, Luiz A. C. A economia brasileira no Império, 1822-1889. Rio de Janeiro: PUC-RIO, 2001. Disponível em: <http://www.economia.puc-rio.br/PDF/td584. pdf>. Acesso em: 18 nov. 2017.

ADORNO, Sergio. Os aprendizes do poder: bacharelismo liberal na política brasileira. São Paulo: Paz e Terra, 1988.

ALVAREZ, Marcos C. A criminologia no Brasil ou como tratar desigualmente os desiguais. DADOS - Revista de Ciências Sociais, Rio de Janeiro, v. 45, n. 4, p. 677-704, 2002. 
BAPTISTA, Bárbara L.; LIMA, Roberto K. de. Como a Antropologia pode contribuir para a pesquisa jurídica? Um desafio metodológico. Anuário Antropológico 2013, Brasília, v. 39, n. 1, p. 9-37, 2014.

BRASIL. Lei de 11 de agosto de 1827. Crêa dous Cursos de sciencias Juridicas e Sociaes, um na cidade de S. Paulo e outro na de Olinda. Chancellaria-mór do Imperio do Brazil. Rio de Janeiro, 1827. Disponível em: <http://www.planalto.gov.br/ccivil_03/leis/lim/LIM.11-08-1827.htm>. Acesso em: 18 nov. 2017.

BRASIL. Portaria $n^{\circ} 1.886$, de 30 de dezembro de 1994. Fixa as diretrizes curriculares e o conteúdo mínimo do curso jurídico. Diário Oficial da União. Poder Executivo, Brasília, DF, 1994. Disponível em: <https://www.migalhas.com.br/arquivo_artigo/art20100108-03. pdf>. Acesso em: 18 nov. 2017.

BRASIL. Resolução CNE/CES n 9, de 29 de setembro de 2004. Institui as Diretrizes Curriculares Nacionais do Curso de Graduação em Direito e dá outras providências. Diário Oficial da União. Poder Executivo, Brasília, DF, 2004. Disponível em: <http://portal. mec.gov.br/cne/arquivos/pdf/rces09_04.pdf>. Acesso em: 18 nov. 2017.

BRASIL. Lei $\mathrm{n}^{\circ}$ 11.343, de 23 de agosto de 2006. Institui o Sistema Nacional de Políticas Públicas sobre Drogas (Sisnad), prescreve medidas para prevenção do uso indevido, atenção e reinserção social de usuários e dependentes de drogas, estabelece normas para repressão à produção não autorizada e ao tráfico ilícito de drogas e define crimes e dá outras providências. Diário Oficial da União. Poder Executivo, Brasília, DF, 2006. Disponível em: <http://www.planalto.gov.br/ccivil_03/_ato2004-2006/2006/lei/l11343. htm>. Acesso em: 18 nov. 2017.

CARNEIRO, Aparecida S. A construção do outro como Não-Ser como fundamento do Ser. São Paulo: FEUSP, 2005.

DAFLON, Verônica T.; FERES JÚNIOR, João; CAMPOS, Luiz A. Ações afirmativas raciais no ensino superior público brasileiro: um panorama analítico. Cadernos de Pesquisa, v. 43, n. 148, p. 302-327, jan./abr. 2013.

FALCÃO, Joaquim A. Cultura jurídica e democracia: a favor da democratização do Judiciário. In: LAMOUNIER, Bolivar et al. Direito, cidadania e participação. São Paulo: TA Queiroz, 1981.

FLAUZINA, Ana Luiza P.; FREITAS, Felipe S. Do paradoxal privilégio de ser vítima: terror de Estado e a negação do sofrimento negro no Brasil. RBCCrim - Revista IBCCRIM, v. 1, n. 135, p. 15-32, 2017. 
GUIMARÃES, Antônio S. A. Racismo e antirracismo no Brasil. São Paulo: Editora 34, 1999.

GUIMARÃES, Antônio S. A. Entre o medo de fraudes e o fantasma das raças. Horizontes Antropológicos, Porto Alegre, v. 11, n. 23, p. 215-217, 2005.

INSTITUTO BRASILEIRO DE GEOGRAFIA E ESTATÍstICA. Censo Demográfico 2010: Características da população e dos domicílios - Resultados do universo. Brasília: Ministério do Planejamento, Orçamento e Gestão; Instituto Brasileiro de Geografia e Estatística, 2011.

LAMY FILHO, Alfredo. A crise do ensino jurídico e a experiência do CEPED. Revista do Instituto dos Advogados Brasileiros, Rio de Janeiro, v. 6, n. 18, p. 151-164, 1972.

LEITE, Maria Cecília L.; DIAS, Renato D. Educação jurídica na contemporaneidade e imagens. In: SALES, J. A. M.; FARIAS, I. M. S. Didática e Prática de Ensino na relação com a Sociedade. Fortaleza: Eduece, 2014.

MARCHESE, Fabrizio. A crise do ensino jurídico no Brasil a as possíveis contribuições da educação geral. 2006. 259 f. Dissertação (Mestrado em Educação) - Universidade Estadual de Campinas, Campinas, 2006.

MOREIRA, Adilson J. Miscigenando o círculo do poder: ações afirmativas, diversidade racial e sociedade democrática. Revista da Faculdade de Direito da UFPR, Curitiba, v. 61, n. 2, p. 117-148, maio/ago. 2016

MUSSE, Luciana B.; FREITAS FILHO, Roberto. Docência em Direito no Brasil: uma carreira profissional? Revista Jurídica da Presidência, Brasília, v. 17, n. 111, p. 173-203, fev./maio 2015.

MUNANGA, Kabengele. Políticas de ação afirmativa em benefício da população negra no Brasil: um ponto de vista em defesa de cotas. In: SILVÉRIO, V. R.; GONÇALVES e SILVA, B. (Org.). Educação e ações afirmativas: entre a injustiça simbólica e a injustiça econômica. Brasília: Instituto Nacional de Estudos e Pesquisas Educacionais Anísio Teixeira, 2003. p. 111-128.

NOBRE, Marcos. Apontamentos sobre a Pesquisa em Direito no Brasil. São Paulo: Cadernos Direito GV, 2013.

OLIVEN, Ruben G. Brasil, uma modernidade tropical. Etnográfica, v. III, n. 2, p. 409-427, 1999. 
PINTO, Paulo Gabriel Hilu da Rocha. Ação afirmativa, identidades e práticas acadêmicas: Uma etnografia das cotas para negros na UERJ. In: FERES JÚNIOR, João; ZONINSEIN, Jonas. Ação afirmativa e universidade: experiências nacionais comparadas. Brasília: Editora UnB, 2005. p. 136-166.

RODRIGUES, Horácio. A crise do ensino jurídico de graduação no Brasil contemporâneo: indo além do senso comum. Florianópolis: CPGD/UFSC, 1992. 397 p.

SANTOS, Jocélio Teles dos; QUEIROZ, Delcele Mascarenhas. Sistema de cotas: um debate dos dados à manutenção de privilégios e de poder. Educação e Sociedade, Campinas, v. 27, n. 96 - Especial, p. 717-737, out. 2006.

SANTOS, Juarez C. A criminologia radical. Rio de Janeiro: Forense, 1981.

SCHUCMAN, Lia V. Entre o "encardido", o "branco" e o "branquíssimo": raça, hierarquia e poder na construção da branquitude paulistana. 2012. 160 f. Tese (Doutorado em Psicologia Social) - Instituto de Psicologia da Universidade dde São Paulo, São Paulo, 2012.

SINHORETTO, Jacqueline; SILVESTRE, Giane; SCHLITTLER, Maria C. Desigualdade racial e segurança pública em São Paulo: letalidade policial e prisões em flagrante. São Paulo: UFSCAR, v. 2, 2014.

TEIXEIRA MENDES, Regina. Igualdade à brasileira: cidadania como instituto jurídico no Brasil. Revista de Ciências Criminais, n. 13, 2005.

TEIXEIRA, Manuel. A habitação popular no século XIX - características morfológicas, a transmissão de modelos: as ilhas do Porto e os cortiços do Rio de Janeiro. Análise Social, v. XXIX, n. 127, p. 555-579, 1994.

VARGAS, Daniel. Jurista criativo. Cadernos FGV Direito Rio, Rio de Janeiro, v. 9, Educação e Direito, p. 83-104, 2014. Disponível em: <http://bibliotecadigital.fgv.br/dspace/ bitstream/handle/10438/12036/Cadernos\%20FGV\%20DIREITO\%20RIO\%20-\%20 Vol.\%209.pdf;sequence=2>. Acesso em: 20 nov. 2017.

VARGAS, João C. A diáspora negra como genocídio: Brasil, Estados Unidos ou uma geografia supranacional da morte e suas alternativas. Revista da ABPN, v. 1, n. 2, p. 3165, jul./out. 2010.

VARGAS, João C. Por uma Mudança de Paradigma: Antinegritude e Antagonismo Estrutural. Revista de Ciências Sociais, Fortaleza, v. 48, n. 2, p. 83-105, jul./dez. 2017. 
VIANNA, Francisco José de Oliveira. Instituições políticas brasileiras. Rio de Janeiro: Record, 1974.

VIEIRA, Oscar V. Desafios do ensino jurídico num mundo em transição: o projeto da Direito GV. Revista de Direito Administrativo, Rio de Janeiro, v. 261, p. 375-407, set./dez. 2012.

WAISELFISZ, Julio J. Mapa da violência 2016: homicídios por arma de fogo no Brasil. Brasília: Flacso Brasil, 2016.

\section{Poliana da Silva Ferreira}

Mestranda em Direito e Desenvolvimento pela Escola de Direito de São Paulo, da Fundação Getúlio Vargas (FGV). Pesquisadora do Grupo de Pesquisa em Criminologia da Universidade do Estado da Bahia (UNEB) e do Núcleo de Estudos sobre o Crime e a Pena da FGV. Bolsista FAPESP 2017/00239-4. Graduada em Direito pela UNEB.

polianasferreira@hotmail.com 